\title{
Vitamin D status and its relation with insulin resistance and VDR-Fokl polymorphism in Iranian non-melanoma skin cancer (NMSC) patients: a case- control study
}

\section{Fatemeh Rezaiian}

Shaheed Beheshti University of Medical Sciences

Sayed Hossein Davoodi

Shaheed Beheshti University of Medical Sciences

\section{Bahareh Nikooyeh}

Shaheed Beheshti University of Medical Sciences

Amir Houshang Ehsani

Tehran University of Medical Sciences

Ali Kalayi

Shaheed Beheshti University of Medical Sciences

Nastaran Shariatzadeh

Shaheed Beheshti University of Medical Sciences

\section{Maliheh Zahedirad}

Shaheed Beheshti University of Medical Sciences

Tirang R. Neyestani ( $\nabla$ neytr@yahoo.com )

https://orcid.org/0000-0002-0953-2594

\section{Research article}

Keywords: sun exposure; non-melanoma skin cancer; polymorphisms; insulin resistance

Posted Date: September 24th, 2019

DOI: https://doi.org/10.21203/rs.2.10291/v2

License: (1) This work is licensed under a Creative Commons Attribution 4.0 International License. Read Full License 


\section{Abstract}

Background: Sunlight exposure, the main source of endogenous vitamin D synthesis, may increase the risk of non-melanoma skin cancer (NMSC) development. Vitamin D receptor (VDR) polymorphisms are associated with $25(\mathrm{OH}) \mathrm{D}$ levels, cancer development and insulin resistance. This study was aimed to examine the associations among vitamin D status, VDR Fokl polymorphism, insulin resistance and NMSC. Methods: This case-control study included 73 diagnosed cases of NMSC and 72 healthy controls from dermatology clinics at Razi Hospital, Tehran, Iran. A questionnaire was used to assess sunlight exposure. The extracted DNA from whole blood samples were genotyped. Fasting serum 25-hydroxyvitaminD $(25(\mathrm{OH}) \mathrm{D})$ ), lipid profile, glucose, and insulin were measured. To evaluate insulin resistance, HOMA-IR formula was used. Results: We found a significant higher duration of cumulative sunlight exposure in cases compared with controls $(\mathrm{p}<0.001)$. However, $25(\mathrm{OH}) \mathrm{D}$ concentrations were not significantly different between cases and controls ( $30 \pm 15$ vs. $29 \pm 15 \mathrm{ng} / \mathrm{mL}, p=0.78)$. Higher levels of insulin $(p=0.004)$ and HOMA-IR score $(p=0.019)$ were observed in $\mathrm{Ff}$ and $\mathrm{ff}$ genotype of Fokl. We did not observe any significant increased risk of NMSC due to $f$ allele, as compared with FF (OR $=2.33,95 \% \mathrm{Cl} 0.81-6.75, p=0.12)$. The components of lipid profile, fasting serum glucose, iPTH and anthropometric measures did not differ significantly across VDR genotypes. Conclusion: In conclusion, sunlight exposure was associated with NMSC risk. VDR Fokl polymorphisms appears to influence insulin resistance in the NMSC patients. Keywords: sun exposure; non-melanoma skin cancer; polymorphisms; insulin resistance

\section{Introduction}

Suboptimal vitamin $\mathrm{D}$ status reported from many countries in different age and sex subpopulations is now considered a serious global health problem (1). The importance of vitamin D deficiency (VDD) is not confined to the deleterious effects on musculoskeletal system. A growing body of evidence shows the predisposing effect of VDD in many human pathologies including cardiovascular disease, diabetes, autoimmune disorders (2) and certain cancers (3-4). Skin cancers are among the most common types of human neoplasms (5). In Iran the incidence of skin cancers is increasing (6) comprising approximately $15 \%$ of all cancers (7).

Exploration of vitamin D receptor (VDR) on a vast variety of tissues and cells including basal cell and squamous cell carcinomas indicated new roles for the vitamin (8). Though several lines of evidence indicate a protective role for vitamin $D$ against colorectal, breast, prostate and pancreatic cancers (9) , the association of vitamin $D$ and skin cancers is intriguing. While the main natural source of vitamin $D$ is solar ultra violet beam (UVB), direct exposure to the same wavelength of UVB has been known as the major culprit of skin cancers (10). It is, therefore, speculated that subjects with skin cancers may have longer periods of sun exposure and hence higher vitamin D status than the general population (11).

The possible link between insulin resistance (IR) and human cancers, including skin malignancies, can be a new argument (12). The associations between IR and several malignancies including colon, liver, pancreas (13), endometrium (14), breast (15), lung (16) and thyroid cancers (17) have been reported. The ameliorating 
effect of vitamin D on IR has been shown by clinical trials (18). Whether this effect can mediate any anticancer property of vitamin $\mathrm{D}$ is still unknown.

Despite previous studies on relationship between 25(OH)D3 and IR, the molecular mechanisms of the role of VDR in insulin resistance remains to be determined (19-21). The limited evidence available suggests that two common VDR gene polymorphisms (Bsml and Fokl) might have an effect on BMI, insulin resistance and serum HDL-cholesterol (21-24). However, little information is available regarding this association in cancer patients.

On the other hand, the nutrigenetic effect of VDR polymorphisms on response to vitamin $D$ intake has been already documented (25). VDR polymorphism is characterized by altered expression levels leading to decrease or increase in vitamin D activity (26-27). Fokl (rs2228570) polymorphism is the only known polymorphism that generates an altered protein (28). VDR polymorphisms have been linked to several cancer risks including prostate, breast, bowel (29-30) and skin malignancies (31-32). However, the associations of VDR polymorphisms with skin cancer risk has not been understood clearly yet (33). Data from a meta-analysis suggest that there might be a possible positive link between VDR Fokl (rs2228570) and Bsml (rs1544410) polymorphisms and cutaneous malignant melanoma (CMM) and non-melanoma skin cancer (NMSC) risks (34). However, in a systematic review no significant association was observed between Taql (rs731236), Bsml (rs1544410) and Fokl (rs2228570) polymorphisms and NMSC risk (33). With regard to the possible role of vitamin D in skin cancers and notably NMSCs, several issues may raise: (1) Do NMSC patients have longer duration of occupational direct sun exposure than unaffected people? And if yes (2) Does it have any influence on their vitamin D status? In other words, do NMSC patients have higher vitamin D status as compared to the unaffected people as reported by some studies (35-36)? (3) Is there any association between IR and NMSC? And finally (4) Is there any association among VDR Fokl polymorphisms (rs2228570), vitamin D status and NMSC risk? To answer these questions, a hospital-based case-control study was conducted.

\section{Subjects And Methods}

\section{Participants and Clinical Samples}

This case-control study included 65 participants with a BCC or SCC within 3 months of diagnosis who were visited at the dermatology clinics at Razi Hospital of Tehran University of Medical Sciences in a period between September 2016 and April 2018. The controls were composed of 65 unrelated healthy volunteers who were matched for age and sex to the patients with NMSC (Table I). All participants completed a questionnaire including information on marital status, education level, medication and supplement use history, disease history, sunscreen use and mean hours of daily sun exposure. Participants who were taking any nutritional supplement including vitamin $\mathrm{D}$, calcium, omega-3 and antioxidant, or medications that modify vitamin $\mathrm{D}$ metabolism (corticosteroids, estrogens and calcitonin) for at least 3 months preceding the study, history of any other cancers and renal or liver diseases were excluded from the study. Fasting blood samples were obtained from all participants for DNA genotyping and biochemical analyses. The study procedures were approved by the Research Council and the Ethical Committee of the National Nutrition and 
Food Technology Research Institute (NNFTRI), respectively. All participants signed a written informed consent form.

\section{Anthropometry and blood pressure}

Weight was measured with light clothing and without shoes using a digital scale (Seca 808; Seca, Hamburg, Germany) to the nearest of $0.1 \mathrm{~kg}$. Height was measured using a stadiometer (Seca 216, Seca, Hamburg, Germany) to the nearest of $0.1 \mathrm{~cm}$. Body mass index (BMI) was calculated using the equation body weight $(\mathrm{kg}) /$ height $^{2}(\mathrm{~m})$. BMI was categorized as follows: underweight (<18.5), normal (18.5-24.9) and overweight (> 25.0) in accordance with the 2004 World Health Organization (WHO) recommendations.

Hip circumference $(\mathrm{HC})$ and waist circumference $(\mathrm{WC})$ were both measured by a measuring tape to the nearest $0.1 \mathrm{~cm}$. WC was measured at the approximate midpoint between the lowest rib and iliac crest after a normal expiration. Hip circumference $(\mathrm{HC})$ was also measured at the level of the greater trochanters. Systolic blood pressure (SBP) and diastolic blood pressure (DBP) were measured using a digital sphygmomanometer (BC08; Beurer GmbH, Ulm, Germany).

\section{Laboratory investigations}

\section{Glycemic status and lipid profile}

Fasting serum glucose, total cholesterol, triglycerides (TG), high-density lipoprotein cholesterol (HDL-C) and low-density lipoprotein cholesterol (LDL-C) were determined using enzymatic colorimetric methods (all from Pars Azmoon, Tehran, Iran). Serum insulin was measured by means of an enzyme immunoassay (EIA) kit (Demeditec Diagnostics GmbH, Kiel, Germany). Homeostasis model assessment of insulin resistance (HOMA-IR was used as an index of insulin resistance and was calculated by the following formula (37):

HOMA-IR $=(($ fasting insulin $(\mathrm{mU} / \mathrm{mL}) \times$ fasting glucose $(\mathrm{mg} / \mathrm{dL})) / 405)$

\section{Serum calcidiol and iPTH measurements}

Serum 25(OH)D and iPTH were assayed using EIA kits (both from Euroimmun, Medizinische Labordiagnostika AG, Germany). Subjects were categorized as vitamin D deficient if 25(OH)D concentration was below $20 \mathrm{ng} / \mathrm{ml}$, insufficient with concentrations $20-29 \mathrm{ng} / \mathrm{ml}$ and sufficient with concentrations of at least $30 \mathrm{ng} / \mathrm{ml}(38-41)$.

\subsection{DNA Extraction and Genotyping}

Genomic DNA was isolated from whole blood samples using PrimePrep Genomic DNA isolation kit (GeNet Bio, Daejeon, South Korea) according to the manufacturer's protocol. For VDR Fokl polymorphism (rs2228570) the forward primer was 5'- GTCAAAGTCTCCAGGGTCAG -3', and the reverse primer used was 5'GCCTGCTTGCTGTTCTTAC -3'. Genotyping was done by high-resolution melting (HRM) assay using Step one plus (Applied Biosystems, Foster City, USA). The PCR reactions were carried out in a final volume of 20 $\mu \mathrm{L}$ using the 5x Hot FIREPol HRM Mix (HRM PCR buffer, HotStarTaq Plus DNA Polymerase, nucleotides and EvaGreen dye), $0.3 \mathrm{nM}$ of forward and reverse primers each (final concentration) and $30 \mathrm{ng}$ DNA under the 
following conditions: initial denaturation-activation step at $95^{\circ} \mathrm{C}$ for $15 \mathrm{~min}$, followed by a 40 -cycle program (denaturation at $95^{\circ} \mathrm{C}$ for $15 \mathrm{~s}$, annealing at $61^{\circ} \mathrm{C}$ for 20 seconds, $72^{\circ} \mathrm{C}$ for 20 seconds) and HRM step from 60 to $95^{\circ} \mathrm{C}$ rising at $0.1^{\circ} \mathrm{C}$ per second. Curves for each duplicate were checked on the shape and peak height to meet reproducibility. Normalized and temperature-shifted melting curves from HRM, suggestive of SNP, were distinguished, and direct Sanger sequencing was used to confirm genotyping results from the samples.

\section{Statistical analyses}

Data were expressed as mean \pm SD for continuous variables and frequencies for categorical variables. Normality of data was checked using Kolmogrov-Smirnov test. For between-group comparison of variables, independent sample $t$ test, Mann-Whitney, or $\chi^{2}$ tests were used when appropriate. Means of variables were compared among the different polymorphism groups using ANOVA or Kruskal-Wallis tests for data with normal or non-normal distribution, respectively. Tukey's HD correction for multiple comparisons was applied, as required. The associations between VDR Fokl polymorphism and risk of NMSC were estimated by computing odds ratios (ORs) and 95\% confidence intervals (Cls) using logistic regression analyses. The Hardy-Weinberg equilibrium (HWE) was tested by a goodness-of-fit chi-squared test to compare the observed genotype frequencies with the expected frequencies among controls. All statistical analyses were done with SPSS software IBM SPSS Statistics version 23.A two-tailed value of less than 0.05 was considered statistically significant.

\section{Results}

\section{Characteristics of the study participants}

Overall, 145 participants including 73 NMSC patients and 72 healthy controls were enrolled (Table 1). The mean age of the patients and controls was $56 \pm 9$ and $58 \pm 8$ years, respectively, men consisted the greater proportion of both study groups. Compared with the healthy controls, NMSC subjects were significantly less educated $(p=0.006)$. Anthropometric measures including waist circumference $(p=0.016)$, hip circumference $(p=0.02)$, percentage of visceral fat $(p=0.008)$ and blood pressure $(p=0.001)$ were all significantly greater in cases than in controls. However, BMI did not statistically differ between two groups $(p=0.8)$.

Despite significantly longer duration of sun exposure (including occupational exposure) in cases than in controls $(p<0.001)$, there was no significant between-group difference in concentrations of circulating 25(OH)D and distribution of vitamin D status (Table 2). Though fasting serum glucose showed no significant between-group difference, serum concentrations of insulin as well as HOMA-IR were both higher in NMSC group than in controls. Other variables did not show any significant between-group difference.

Our analyses revealed that the frequencies of VDR variants in our study population were in HW equilibrium $\left(\right.$ chi $^{2}$ value $=5.094, p=0.07$ for control). The genotypes of FF, Ff and ff were $57 \%, 26 \%, 16 \%$ in NMSC cases and $68.1 \%, 23 \%, 8 \%$ in healthy controls, respectively. The results of the evaluation of the association between VDR Fokl polymorphism (rs2228570) and NMSC risk are demonstrated in Table 3. Logistic regression analysis did not show any significant increased risk of NMSC due to f allele (ACG codon), as compared with FF (ATG codon). 
On comparison of different variables among VDR Fokl variants, the measures of serum insulin and HOMAIR were significantly higher in $\mathrm{Ff}$ and $\mathrm{ff}$ than in the FF genotype (Table 4). WHR values were higher in $\mathrm{ff}$ than in $F f$ and $F F$ variants $(p=0.032)$. There was no significant between-Fokl-variant difference in other variables.

\section{Discussion}

We found a significant association between cumulative (including occupational) sunlight exposure and increased risk of NMSC. However, no significant difference in circulating concentrations of calcidiol between NMSC subjects and their healthy counterparts was detected. A great body of evidence indicates that chronic sunlight exposure induces most non-melanoma skin cancers (42). It is roughly estimated that only $25 \%$ of life span UV exposure occurs before the age of 18 (43). Despite the potential role of sun exposure in skin cancer development and also the potential protective effect of vitamin $D$ against various malignancies, it is still the matter of debate that how much sunlight is needed to provide adequate levels of circulating calcidiol without exerting carcinogenicity. Findings from studies on the association between circulating calcidiol concentrations and NMSC convey conflicting results. Some case-control studies indicated an association between higher prediagnostic concentrations of circulating calcidiol and an increased risk of basal cell carcinoma (BCC) development (35-36). Along the same line of evidence, some prospective cohort studies reported an increased risk of non-melanoma and melanoma skin cancers with increasing concentrations of serum 25(OH)D (44-45). In contrast, a case-control study from Iran reported high prevalence of vitamin D deficiency in both BCC patients and healthy people (46). One of the reasons of these discrepancies may be the very high prevalence of suboptimal serum calcidiol concentrations in Iran (47-50) which may veil any possible effect of vitamin D status on NMSC risk. Longer duration of sun exposure in the NMSC group despite no significant difference in circulating calcidiol between two groups might have contributed in development of the disease.

We found no significant association between VDR Fokl polymorphisms (rs2228570) and NMSC risk. Accordingly, in a nested case-control study within Nurses' Health Study, there was no significant association between Fokl ff genotype and skin cancers whereas Bsml BB variant was associated with increased risk of squamous cell carcinoma (SCC) (51). In contrast with this report, a meta-analysis suggested a possible role for polymorphisms of VDR Fokl and Bsml in relation to skin cancer risks including malignant melanoma and NMSC (34). Altogether, previous studies investigating the association of VDR polymorphisms with NMSC risk have generated controversial results which can be explained by genetic variations in populations and types of data collected.

Several studies have examined the possible interactions between VDR polymorphisms and vitamin $D$ status $(25,52)$. However, we found no significant difference in circulating calcidiol concentrations among VDR Fokl variants. But interestingly, Fok-I Ff and ff SNPs were related to increased insulin resistance in the whole study population. Furthermore, these genotypes were related to higher blood pressure, BMI, WC, total cholesterol and LDL-C in both NMSC and control participants. Our findings are consistent with previous reports (53). 
VDR Fokl polymorphism has been previously found to be associated with anthropometric and biochemical components of metabolic syndrome (MetS), as in a study VDR Bsml polymorphism was associated with BMI whereas FokI VDR polymorphism was related to insulin sensitivity and serum HDL cholesterol in men (22). In a case-control study, FokI VDR was significantly associated with the components of lipid profile, calcidiol and interleukin (IL)-6 plasma levels in patients without MetS and associated with HOMA-IR, serum insulin, 25(OH)D and IL-6 levels as well as WC and BMI in MetS group (21). These findings are largely in accord with those of our study. Notwithstanding, VDR gene is not the foremost determinant of 25(OH)D serum concentrations, as stated by genome-wide association (GWA) experiments (54-55). However, the evidence is indicative of the potential role of VDR gene in the pleiotropic functions of $1,25(\mathrm{OH})_{2} \mathrm{D}_{3}$ and in insulin secretion (56). The role of increased IR in development of NMSCs needs to be clarified by further studies.

To the best of our knowledge, this is the first report of a possible association between Fok-I VDR gene polymorphism and IR in a NMSC population. As IR and type 2 diabetes are caused by a set of interplays between genetic and lifestyle, large-scale, population-based studies are essential to further explore the relationship between this SNP and IR and its association with skin cancer development.

Some limitations of this study are acknowledged. Participants in a hospital-based case-control study may not be representative of the whole community. Secondly, comparison of the results from different studies for association between sunlight exposure and skin cancer could be very difficult because of the various methods used to estimate sunlight exposure. In case-control studies recall bias occurs because cases tend to recall past exposures more accurately than controls. Moreover, self-reporting of sunlight exposures in the past may result in measurement error due to difficulty in recalling sun exposure habits. Like some other studies, some important NMSC risk factors, including family history and skin type of white subjects were not evaluated. However, some studies reported that Iranian skin types, based on Fitzpatrick scale, can be classified as "lightly pigmented", i.e. skin types I to IV from north to south, respectively, based on the Fitzpatrick scale (57-58) and there is no relationship between skin type and minimal erythermal dose (59). We did not examine any possible association between NMSC and other VDR polymorphisms, including Bsml.

Our data on vitamin D status were limited to a single measurement of $25(\mathrm{OH}) \mathrm{D}$ in the blood sample obtained at the enrollment time and this measurement does not necessarily reflect vitamin $D$ status of the subjects in critical periods of life mainly childhood and young adult. Future well-designed prospective studies are to be performed to overcome the aforementioned limitations.

\section{Conclusion}

In conclusion, our results suggest that VDR Fok/polymorphisms are not significantly associated with the development of NMSC in Iranian subjects. However, this lack of association might be due to our study's small sample size and low genetic power to detect disease susceptibility. 
The present study suggests an interaction between VDR Fokl polymorphism and measures of insulin resistance and circulating 25(OH)D. FokI VDR polymorphisms may be linked to insulin resistance and might represent a genetic determinant for developing MetS in NMSC patients. These findings have clinical implications. Some studies revealed that components of MetS including raised blood pressure and deranged glucose and lipid metabolism may contribute in development of skin cancers (60) and also treatment of MetS can improve skin conditions (61). Therefore, weight control, having a healthy diet and improvement of vitamin D status may all help NMSC prevention. Further studies on large population are essential, besides the genome wide association studies to determine the direct effect of VDR polymorphisms on insulin resistance.

\section{Abbreviations}

BCC: Basal cell carcinoma

BMI: Body Mass Index

DBP: Diastolic blood pressure

EIA: Enzyme immunoassay

HWE: Hardy-Weinberg equilibrium

HC: Hip circumference

HRM: high-resolution melting

HOMA-IR: Homeostasis model assessment of insulin resistance

25(OH)D: 25-hydroxycalciferol

IU: International unit

MetS: Metabolic syndrome

NMSC: Non-melanoma skin cancer

SBP: Systolic blood pressure

SCC: Squamous cell carcinoma

UV: Ultraviolet

VDD: Vitamin D deficiency

VDR: Vitamin D receptor

WC: Waist circumference 


\section{Declarations}

\section{Ethics approval and consent to participate}

The study procedures were approved by the Research Council and the Ethical Committee of the National Nutrition and Food Technology Research Institute (NNFTRI), respectively. All participants signed a written informed consent form.

\section{Consent for publication}

Not applicable

\section{Availability of data and materials}

The raw/processed data required to reproduce these findings cannot be shared at this time as the data also forms part of an ongoing study.

\section{Competing interests}

The authors declare that they have no conflict of interest.

\section{Funding}

This research did not receive any specific grant from any funding agency in the public, commercial or notfor-profit sector.

\section{Authors' contributions}

TN and FR designed the study. FR, AK, NS and MZ contributed to sample collection and performed the experiments. BN, TN and FR analysed the data. FR and TN wrote the paper with input from all authors.

\section{Acknowledgement}

This study represents part of a Ph.D. dissertation of Mrs. Fatemeh Rezaiian under the supervision of Professor Tirang R. Neyestani. The assistance of the staff of the Dermatology Clinics of Razi Hospital and especially all the participants is deeply appreciated.

\section{References}


1. Holick MF. Vitamin D and sunlight: strategies for cancer prevention and other health benefits. Clin J Am Soc Nephrol. 2008 Sep;3(5):1548-54. 2. Holick MF. Sunlight and vitamin D for bone health and prevention of autoimmune diseases, cancers, and cardiovascular disease. The American journal of clinical nutrition. 2004;80(6):1678S-88S. 3. Holick MF. The Vitamin D Deficiency Pandemic: a Forgotten Hormone Important for Health. Public Health Reviews. [journal article]. 2010 June 01;32(1):267-83. 4. Jamshidinaeini Y, Akbari ME, Abdollahi M, Ajami M, Davoodi SH. Vitamin D status and risk of breast cancer in Iranian women: a case-control study. Journal of the American College of Nutrition. 2016;35(7):639-46. 5. Bikle DD. Vitamin D and skin cancer. J Nutr. 2004 Dec;134(12 Suppl):3472S-8S. 6. Razi S, Enayatrad M, MohammadianHafshejani A, Salehiniya H, Fathali-loy-dizaji M, Soltani S. The Epidemiology of Skin Cancer and its Trend in Iran. International Journal of Preventive Medicine. 2015 07/16 10/20/received 04/21/accepted;6:64. 7. Keyghobadi N, Rafiemanesh H, Mohammadian-Hafshejani A, Enayatrad M, Salehiniya H. Epidemiology and trend of cancers in the province of Kerman: southeast of Iran. Asian Pac J Cancer Prev. 2015;16(4):1409-13. 8. Bikle DD. Protective actions of vitamin D in UVB induced skin cancer. Photochem Photobiol Sci. 2012 Dec;11(12):1808-16. 9. Dimitrakopoulou VI, Tsilidis KK, Haycock PC, Dimou NL, Al-Dabhani K, Martin RM, et al. Circulating vitamin D concentration and risk of seven cancers: Mendelian randomisation study. BMJ. 2017;359:j4761-j. 10. Rivas M, Rojas E, Araya MC, Calaf GM. Ultraviolet light exposure, skin cancer risk and vitamin D production. Oncol Lett. 2015 Oct;10(4):2259-64. 11. van der Pols JC, Russell A, Bauer U, Neale RE, Kimlin MG, Green AC. Vitamin D status and skin cancer risk independent of time outdoors: 11-year prospective study in an Australian community. J Invest Dermatol. 2013 Mar;133(3):637-41. 12. Neyestani TR. Vitamin D and Skin Cancer: Meet Sunshine Halfway. Bioactive Dietary Factors and Plant Extracts in Dermatology: Springer; 2013. p. 257-68. 13. Tsugane S, Inoue M. Insulin resistance and cancer: epidemiological evidence. Cancer science. 2010 May;101(5):1073-9. 14. Burzawa JK, Schmeler KM, Soliman PT, Meyer LA, Bevers MW, Pustilnik TL, et al. Prospective evaluation of insulin resistance among endometrial cancer patients. American journal of obstetrics and gynecology. 2011 Apr;204(4):355 e1-7. 15. Duggan C, Irwin ML, Xiao L, Henderson KD, Smith AW, Baumgartner RN, et al. Associations of insulin resistance and adiponectin with mortality in women with breast cancer. Journal of clinical oncology : official journal of the American Society of Clinical Oncology. 2011 Jan 1;29(1):32-9. 16. Petridou ET, Sergentanis TN, Antonopoulos CN, Dessypris N, Matsoukis IL, Aronis K, et al. Insulin resistance: an independent risk factor for lung cancer? Metabolism: clinical and experimental. 2011 Aug;60(8):1100-6. 17. Gursoy A. Rising thyroid cancer incidence in the world might be related to insulin resistance. Medical hypotheses. 2010 Jan;74(1):356. 18. Nikooyeh B, Neyestani TR, Farvid M, Alavi-Majd H, Houshiarrad A, Kalayi A, et al. Daily consumption of vitamin D- or vitamin D + calcium-fortified yogurt drink improved glycemic control in patients with type 2 diabetes: a randomized clinical trial. The American journal of clinical nutrition. 2011 Apr;93(4):764-71. 19. Liu E, McKeown NM, Pittas AG, Meigs JB, Economos CD, Booth SL, et al. Predicted 25-hydroxyvitamin D score and change in fasting plasma glucose in the Framingham offspring study. European journal of clinical nutrition. 2012 Jan;66(1):139-41. 20. Liu E, Meigs JB, Pittas AG, Economos CD, McKeown NM, Booth $\mathrm{SL}$, et al. Predicted 25-hydroxyvitamin D score and incident type 2 diabetes in the Framingham Offspring Study. The American journal of clinical nutrition. 2010 Jun;91(6):1627-33. 21. Mackawy AMH, Badawi MEH. Association of vitamin $\mathrm{D}$ and vitamin $\mathrm{D}$ receptor gene polymorphisms with chronic inflammation, insulin resistance and metabolic syndrome components in type 2 diabetic Egyptian patients. Meta Gene. 2014 2014/12/01/;2:540-56. 22. Filus A, Trzmiel A, Kuliczkowska-Plaksej J, Tworowska U, Jedrzejuk D, Milewicz

Page $10 / 15$ 
A, et al. Relationship between vitamin $\mathrm{D}$ receptor $\mathrm{Bsml}$ and Fokl polymorphisms and anthropometric and biochemical parameters describing metabolic syndrome. The aging male : the official journal of the International Society for the Study of the Aging Male. 2008 Sep;11(3):134-9. 23. Ebrahimof S, Shab-bidar S, Yeganeh MZ, Angoorani P, Abedini S, Jahangir F, et al. Vitamin D receptor gene polymorphisms and cardiometabolic profile in women with hypovitaminosis D. Journal of Nutritional Sciences and Dietetics. 2017;2(2). 24. Han FF, Lv YL, Gong LL, Liu H, Wan ZR, Liu LH. VDR Gene variation and insulin resistance related diseases. Lipids in health and disease. 2017 Aug 19;16(1):157. 25. Neyestani TR, Djazayery A, ShabBidar S, Eshraghian MR, Kalayi A, Shariatzadeh N, et al. Vitamin D Receptor Fok-I polymorphism modulates diabetic host response to vitamin D intake: need for a nutrigenetic approach. Diabetes Care. 2013 Mar;36(3):550-6. 26. Valdivielso JM, Fernandez E. Vitamin D receptor polymorphisms and diseases. Clinica chimica acta. 2006;371(1-2):1-12. 27. Abouzid M, Karazniewicz-Lada M, Glowka F. Genetic Determinants of Vitamin D-Related Disorders; Focus on Vitamin D Receptor. Current drug metabolism. 2018;19(12):1042-52. 28. van Etten E, Verlinden L, Giulietti A, Ramos-Lopez E, Branisteanu DD, Ferreira GB, et al. The vitamin D receptor gene Fokl polymorphism: functional impact on the immune system. European journal of immunology. 2007;37(2):395-405. 29. Vaughan-Shaw P, O'sullivan F, Farrington S, Theodoratou E, Campbell $\mathrm{H}$, Dunlop $\mathrm{M}$, et al. The impact of vitamin $\mathrm{D}$ pathway genetic variation and circulating 25 -hydroxyvitamin $\mathrm{D}$ on cancer outcome: systematic review and meta-analysis. British journal of cancer. 2017;116(8):1092. 30. Hama T, Norizoe C, Suga H, Mimura T, Kato T, Moriyama H, et al. Prognostic significance of vitamin D receptor polymorphisms in head and neck squamous cell carcinoma. PLoS One. 2011;6(12):e29634. 31. Lee YH, Gyu Song G. Vitamin D receptor Fokl, Bsml, Taql, Apal, and EcoRV polymorphisms and susceptibility to melanoma: a meta-analysis. J BUON. 2015;20(1):235-43. 32. Von Schuckmann LA, Law MH, Montgomery GW, Green AC, Van Der Pols JC. Vitamin D pathway gene polymorphisms and keratinocyte cancers: a nested case-control study and meta-analysis. Anticancer research. 2016;36(5):2145-52. 33. Denzer N, Vogt T, Reichrath J. Vitamin D receptor (VDR) polymorphisms and skin cancer: A systematic review. Dermatoendocrinology. 2011 Jul-Sep 07/01 04/28/received 05/07/revised 05/18/accepted;3(3):205-10. 34. Gandini S, Raimondi S, Gnagnarella P, Dore JF, Maisonneuve P, Testori A. Vitamin D and skin cancer: a metaanalysis. Eur J Cancer. 2009 Mar;45(4):634-41. 35. Asgari MM, Tang J, Warton ME, Chren MM, Quesenberry $\mathrm{CP}$, Jr., Bikle D, et al. Association of prediagnostic serum vitamin D levels with the development of basal cell carcinoma. Journal of Investigative Dermatology. 2010 May;130(5):1438-43. 36. Soares AM, Szejnfeld VL, Enokihara MY, Michalany N, Castro CH. High serum 25-hydroxyvitamin D concentration in patients with a recent diagnosis of non-melanoma skin cancer: a case-control study. Eur J Dermatol. 2018 Oct 1;28(5):64953. 37. Matthews DR, Hosker JP, Rudenski AS, Naylor BA, Treacher DF, Turner RC. Homeostasis model assessment: insulin resistance and beta-cell function from fasting plasma glucose and insulin concentrations in man. Diabetologia. 1985 Jul;28(7):412-9. 38. Holick MF. Vitamin D Deficiency. New England Journal of Medicine. 2007;357(3):266-81. 39. Chapuy MC, Preziosi P, Maamer M, Arnaud S, Galan P, Hercberg $S$, et al. Prevalence of vitamin D insufficiency in an adult normal population. Osteoporosis international : a journal established as result of cooperation between the European Foundation for Osteoporosis and the National Osteoporosis Foundation of the USA. 1997;7(5):439-43. 40. Holick MF, Siris ES, Binkley N, Beard MK, Khan A, Katzer JT, et al. Prevalence of Vitamin D inadequacy among postmenopausal North American women receiving osteoporosis therapy. The Journal of clinical endocrinology and metabolism. 2005 Jun;90(6):3215-24. 41. Bischoff-Ferrari HA, Giovannucci E, Willett WC, 
Dietrich T, Dawson-Hughes B. Estimation of optimal serum concentrations of 25-hydroxyvitamin D for multiple health outcomes. The American journal of clinical nutrition. 2006 Jul;84(1):18-28. 42. Holick MF, editor. Sun Exposure, Vitamin D Metabolism, and Skin Cancer: In Response. Mayo Clinic proceedings; 2004: Elsevier. 43. lannacone MR, Wang W, Stockwell HG, O'Rourke K, Giuliano AR, Sondak VK, et al. Patterns and timing of sunlight exposure and risk of basal cell and squamous cell carcinomas of the skin - a casecontrol study. BMC Cancer. 2012 2012/09/20;12(1):417. 44. Afzal S, Nordestgaard BG, Bojesen SE. Plasma 25-hydroxyvitamin $D$ and risk of non-melanoma and melanoma skin cancer: a prospective cohort study. $J$ Invest Dermatol. 2013 Mar;133(3):629-36. 45. Eide MJ, Johnson DA, Jacobsen GR, Krajenta RJ, Rao DS, Lim $\mathrm{HW}$, et al. Vitamin D and nonmelanoma skin cancer in a health maintenance organization cohort. Arch Dermatol. 2011 Dec;147(12):1379-84. 46. Darjani A, Mehrdad SM, Zahedi TR, Alizadeh N, Eftekhari H, Rafiee $\mathrm{R}$, et al. Association between Serum Vitamin D Levels and Basal Cell Carcinoma (BCC). Journal of Skin and Stem Cell. 2017;4(3). 47. Nikooyeh B, Abdollahi Z, Hajifaraji M, Alavi-majd H, Salehi F, Yarparvar AH, et al. Vitamin D status and cardiometabolic risk factors across latitudinal gradient in Iranian adults: National food and nutrition surveillance. Nutrition and health. 2017;23(2):87-94. 48. Nikooyeh B, Abdollahi Z, Hajifaraji M, Alavi-Majd H, Salehi F, Yarparvar AH, et al. Vitamin D status, latitude and their associations with some health parameters in children: National Food and Nutrition Surveillance. Journal of tropical pediatrics. 2016;63(1):57-64. 49. Nikooyeh B, Abdollahi Z, Hajifaraji M, Alavi-Majd H, Salehi F, Yarparvar AH, et al. Healthy changes in some cardiometabolic risk factors accompany the higher summertime serum 25hydroxyvitamin D concentrations in Iranian children: National Food and Nutrition Surveillance. Public health nutrition. 2018:1-9. 50. Neyestani TR, Hajifaraji M, Omidvar N, Eshraghian MR, Shariatzadeh N, Kalayi A, et al. High prevalence of vitamin D deficiency in school-age children in Tehran, 2008: a red alert. Public Health Nutr. 2012 Feb;15(2):324-30. 51. Han J, Colditz GA, Hunter DJ. Polymorphisms in the MTHFR and VDR genes and skin cancer risk. Carcinogenesis. 2007;28(2):390-7. 52. Karonova T, Grineva E, Belyaeva O, Bystrova A, Jude EB, Andreeva A, et al. Relationship between vitamin D status and vitamin D receptor gene polymorphisms with markers of metabolic syndrome among adults. Frontiers in endocrinology. 2018;9. 53. Schuch NJ, Garcia VC, Vivolo SR, Martini LA. Relationship between Vitamin D Receptor gene polymorphisms and the components of metabolic syndrome. Nutrition journal. 2013 Jul 15;12:96. 54. O'Brien KM, Sandler DP, Shi M, Harmon QE, Taylor JA, Weinberg CR. Genome-wide association study of serum 25-hydroxyvitamin D in US women. Frontiers in genetics. 2018;9:67. 55. Sapkota BR, Hopkins R, Bjonnes A, Ralhan S, Wander GS, Mehra NK, et al. Genome-wide association study of $25(\mathrm{OH})$ vitamin D concentrations in Punjabi Sikhs: results of the Asian Indian diabetic heart study. The Journal of steroid biochemistry and molecular biology. 2016;158:149-56. 56. Zhao Y, Liao S, He J, Jin Y, Fu H, Chen X, et al. Association of vitamin D receptor gene polymorphisms with metabolic syndrome: a case-control design of population-based cross-sectional study in North China. Lipids in health and disease. 2014 Aug 9;13:129. 57. Kordi M, Fakari FR, Mazloum SR, Layegh P. Quality of life evaluation in Iranian postpartum women with and without striae gravidarum. Iranian journal of psychiatry and behavioral sciences. 2016;10(2). 58. Lucas RM, McMichael AJ, Armstrong BK, Smith WT. Estimating the global disease burden due to ultraviolet radiation exposure. International journal of epidemiology. 2008;37(3):654-67. 59. Halaji Z, Abousaeedi E, Balighi K. The relationship of skin type with minimal erythemal dose (MED). Iranian Journal of Dermatology. 2005;8(30):101-3 [Persian]. 60. Nagel G, Bjørge T, Stocks T, Manjer J, Hallmans G, Edlinger M, et al. Metabolic risk factors and skin cancer in the Metabolic Syndrome and Cancer Project (Me-Can). British Journal of Dermatology. 2012;167(1):59-67. 
61. Stefanadi EC, Dimitrakakis G, Antoniou CK, Challoumas D, Punjabi N, Dimitrakaki IA, et al. Metabolic syndrome and the skin: a more than superficial association. Reviewing the association between skin diseases and metabolic syndrome and a clinical decision algorithm for high risk patients. Diabetol Metab Syndr. 2018;10:9.

\section{Tables}

Table 1. Comparison of age, gender, duration of sun exposure and certain anthropometric data of NMSC subjects and healthy controls

\begin{tabular}{|c|c|c|c|}
\hline characteristic & $\begin{array}{c}\text { NMSC } \\
(n=73)\end{array}$ & $\begin{array}{l}\text { Controls } \\
(n=72)\end{array}$ & $P$ value \\
\hline Age (years), Mean \pm SD & $56 \pm 9$ & $58 \pm 8$ & 0.36 \\
\hline \multicolumn{4}{|l|}{ Sex } \\
\hline male & $50(68.5 \%)$ & $43(59.7 \%)$ & 0.30 \\
\hline female & $23(31.5 \%)$ & $29(40.3 \%)$ & \\
\hline \multicolumn{4}{|l|}{ Sun exposure } \\
\hline Negligible & $8(11.0 \%)$ & $8(11.1 \%)$ & \\
\hline $10-60 \mathrm{~min}$ & $13(17.8 \%)$ & $38(52.8 \%)$ & $<0.001$ \\
\hline $60 \mathrm{~min}$ to $2 \mathrm{~h}$ & $8(11.0 \%)$ & $9(12.5 \%)$ & \\
\hline$>2 \mathrm{~h}$ & $44(60.3 \%)$ & $17(23.6 \%)$ & \\
\hline $\mathrm{BMI}\left(\mathrm{kg} / \mathrm{m}^{2}\right)$ & $28.04 \pm 4.3$ & $27.88 \pm 3.8$ & 0.80 \\
\hline Waist Circumference (cm) & $101 \pm 10$ & $97 \pm 9$ & 0.016 \\
\hline Hip Circumference (cm) & $105.4 \pm 7$ & $102.6 \pm 6$ & 0.02 \\
\hline WHR & $0.95 \pm 0.05$ & $0.94 \pm 0.05$ & 0.14 \\
\hline \multicolumn{4}{|l|}{ Body fat (\%) } \\
\hline Truncal fat & $35.7 \pm 10$ & $34.8 \pm 8$ & 0.53 \\
\hline Visceral fat & $14.3 \pm 5$ & $12.2 \pm 4$ & 0.008 \\
\hline DBP (mm Hg) & $13.1 \pm 2.0$ & $12.1 \pm 1.6$ & 0.001 \\
\hline SBP (mm Hg) & $8.3 \pm 2$ & $7.3 \pm 1$ & $<0.001$ \\
\hline
\end{tabular}

BMI: body mass index; DBP: diastolic blood pressure; SBP: systolic blood pressure; WHR: waist to hip ratio 
Table 2. Comparison of vitamin D, glycemic and lipidemic status between NMSC patients and healthy controls

\begin{tabular}{|c|c|c|c|}
\hline Variable & Cases $\left(n_{1}=73\right)$ & Controls $\left(\mathrm{n}_{2}=72\right)$ & p-value \\
\hline $25(\mathrm{OH}) \mathrm{D}(\mathrm{ng} / \mathrm{mL})$ & $30 \pm 15$ & $29 \pm 15$ & 0.78 \\
\hline Deficient (<20ng/mL), n(\%) & $20(27.4)$ & $22(30.6)$ & \\
\hline Insufficient (20-29.9 ng/mL), n(\%) & $23(31.5)$ & $21(29.2)$ & 0.9 \\
\hline Sufficient (>30ng/mL), $\mathrm{n}(\%)$ & $30(41.1)$ & $29(40.3)$ & \\
\hline iPTH $(\mathrm{pg} / \mathrm{mL})$ & $46.0 \pm 20$ & $40.5 \pm 23$ & 0.14 \\
\hline Fasting serum glucose $(\mathrm{mg} / \mathrm{dL})$ & $97.7 \pm 18$ & $94.7 \pm 34$ & 0.52 \\
\hline Insulin $(\mu \mathrm{IU} / \mathrm{mL})$ & $14.8 \pm 9$ & $12.2 \pm 6$ & 0.048 \\
\hline HOMA-IR & $3.7 \pm 2.8$ & $2.8 \pm 1.8$ & 0.037 \\
\hline Triglyceride(mg/dL) & $129.8 \pm 75$ & $133.3 \pm 68$ & 0.77 \\
\hline $\mathrm{HDL}(\mathrm{mg} / \mathrm{dL})$ & $49.2 \pm 9$ & $48.8 \pm 10$ & 0.83 \\
\hline $\mathrm{LDL}(\mathrm{mg} / \mathrm{dL})$ & $106.3 \pm 27$ & $105.0 \pm 27$ & 0.78 \\
\hline Total cholesterol(mg/dL) & $180.6 \pm 34$ & $179.8 \pm 35$ & 0.9 \\
\hline
\end{tabular}

HOMA-IR: homeostasis model assessment of insulin resistance; iPTH: Intact parathyroid hormone

Table 3. Comparison of distribution of different VDR Fok-I SNPs in NMSC patients and healthy controls

\begin{tabular}{llllll}
\hline $\begin{array}{l}\text { Fok-I (rs2228570) } \\
\text { SNP }\end{array}$ & $\begin{array}{l}\text { Cases } \\
\left(\mathbf{n}_{\mathbf{1}}=73\right)\end{array}$ & $\begin{array}{l}\text { Controls } \\
\left(\mathbf{n}_{\mathbf{2}}=\mathbf{7 2}\right)\end{array}$ & OR & $\mathbf{9 5 \%}$ CI & p value \\
\hline & & & & & \\
FF & $42(57 \%)$ & $49(68 \%)$ & - & & \\
Ff & $19(26 \%)$ & $17(23 \%)$ & 2.33 & $0.806-6.75$ & 0.12 \\
ff & $12(16 \%)$ & $6(8 \%)$ & 1.30 & $0.602-2.82$ & 0.50 \\
Ff+ff & $31(42 \%)$ & $23(31 \%)$ & 1.57 & & 0.19 \\
\hline
\end{tabular}

Table 4. Comparison of anthropometric, blood pressure and biochemical measures among VI FokI (rs2228570) genotypes 


\begin{tabular}{|c|c|c|c|c|c|c|}
\hline \multirow[t]{2}{*}{ ariable } & \multicolumn{3}{|c|}{ Genotype $(n=145)$} & \multirow[b]{2}{*}{$\begin{array}{l}\text { Ff+ff } \\
(n=51)\end{array}$} & \multirow[t]{2}{*}{ p value a $^{-}$} & \multirow{2}{*}{$\begin{array}{l}\text { p } \\
\text { value }\end{array}$} \\
\hline & FF $(n=90)$ & Ff $(n=35)$ & Ff $(n=16)$ & & & \\
\hline 'aist(cm) & $98.2 \pm 10$ & $98.8 \pm 9$ & $103.3 \pm 9$ & $100.3 \pm 9$ & 0.13 & 0.21 \\
\hline ip (cm) & $6 \pm 7$ & $104.4 \pm 6$ & $105.2 \pm 6$ & $104.7 \pm 6$ & 0.65 & 0.39 \\
\hline HR & $0.94 \pm 0.05$ & $0.94 \pm 0.05$ & $0.98 \pm 0.06$ & $0.95 \pm 0.06$ & 0.03 & 0.21 \\
\hline runcal fat (\%) & $34.9 \pm 9$ & $34.8 \pm 8$ & $38.2 \pm 8$ & $35.9 \pm 8$ & 0.35 & 0.25 \\
\hline isceral fat (\%) & $12.9 \pm 4$ & $14.0 \pm 4$ & $13.7 \pm 4$ & $13.9 \pm 4$ & 0.50 & 0.51 \\
\hline MI $\left(\mathrm{kg} / \mathrm{m}^{2}\right)$ & $27.6 \pm 4$ & $28.3 \pm 3$ & $28.8 \pm 3$ & $28.4 \pm 3$ & 0.48 & 0.26 \\
\hline $\mathrm{BP}(\mathrm{mmHg})$ & $12.5 \pm 1.9$ & $13.0 \pm 1.8$ & $12.2 \pm 1.8$ & $12.7 \pm 1.9$ & 0.32 & 0.52 \\
\hline $\mathrm{BP}(\mathrm{mmHg})$ & $7.8 \pm 1.90$ & $7.9 \pm 1.28$ & $7.3 \pm 1.01$ & $7.7 \pm 1.2$ & 0.40 & 0.60 \\
\hline $\bar{\jmath}(\mathrm{OH}) \mathrm{D}(\mathrm{ng} / \mathrm{mL})$ & $30.6 \pm 16$ & $28.0 \pm 14$ & $30.1 \pm 15$ & $28.7 \pm 14$ & 0.69 & 0.46 \\
\hline 'TH $(\mathrm{p}$ & $41.3 \pm$ & 48.3: & 42.7 & 46.4 & 0.29 & 0.18 \\
\hline SG (mg/dL) & $95.5 \pm 28$ & $99.8 \pm 31$ & $92.0 \pm 12$ & $97.4 \pm 26$ & 0.60 & 0.70 \\
\hline $\operatorname{sulin}(\mu \mathrm{IU} / \mathrm{mL})$ & $12.0 \pm 6$ & $16.5 \pm 9$ & $15.0 \pm 9$ & $16.0 \pm 9.2$ & 0.01 & 0.004 \\
\hline OMA-IR & $2.9 \pm 2.1$ & $4.1 \pm 2.7$ & $3.5 \pm 2.9$ & $3.9 \pm 2.8$ & 0.04 & 0.02 \\
\hline riglyceride $(\mathrm{mg} / \mathrm{dL})$ & $128.1 \pm 70$ & $130.6 \pm 69$ & $154.6 \pm 84$ & $137.8 \pm 74$ & 0.41 & 0.43 \\
\hline $\begin{array}{l}\text { stal } \\
\text { holesterol(mg/dL) }\end{array}$ & $179.5 \pm 34$ & $177.5 \pm 37$ & $189.8 \pm 33$ & $181.3 \pm 36$ & 0.48 & 0.77 \\
\hline $\mathrm{DL}-\mathrm{C}(\mathrm{mg} / \mathrm{dL})$ & $49.6 \pm 10$ & $46.9 \pm 9$ & $50.2 \pm 9$ & $47.9 \pm 9$ & 0.33 & 0.32 \\
\hline $\mathrm{DL}-\mathrm{C}(\mathrm{mg} / \mathrm{dL})$ & $104.9 \pm 26$ & $106.1 \pm 31$ & $108.8 \pm 23$ & $106.9 \pm 28$ & 0.87 & 0.68 \\
\hline
\end{tabular}

${ }^{a} \mathrm{p}$ values stands for difference between VDR FokI genotypes (FF, Ff, ff); P-values are obtained from ANOVA with post hoc Tukey HSD

${ }^{\mathrm{b}} \mathrm{p}$ values stands for difference between VDR FokI FF and Ff+ff genotypes. 